Tracey Trottier

Indiana University South Bend

Montgomery Van Wart

California State University

XiaoHu Wang

University of Central Florida

\title{
Examining the Nature and Significance of Leadership in Government Organizations
}

Though the mainstream organizational literature has advanced in the last 20 years with the integration of transformational and distributed leadership theories, as well as genuine attempts at comprehensive models, the public sector literature has lagged, especially in utilizing large-scale empirical studies. This study takes advantage of a very large government data set to test the utility of one of the best known theories, the "full range" leadership theory of Bernard Bass. It addresses three important research questions: How inclusive is Bass's operational definition of leadership? How much of an impact do Bass's leadership competencies have on follower satisfaction? Finally, how important is transformational leadership compared to transactional leadership in government settings? The results indicate that Bass's broad definition of leadership comes quite close to capturing what federal employees perceive to be effective leadership. The relationship between good leadership in an organization and follower satisfaction is also presented as an important outcome in the federal government. Finally, both transactional and transformational leadership are perceived as important in the federal government, although transformational leadership is considered slightly more important even after shifting one important factor, individualized consideration, back to the transactional model.

$\mathrm{T}$ hough the mainstream organizational literature has advanced in the last 20 years with the integration of transformational and distributed leadership theories, as well as genuine attempts at comprehensive models, the public sector literature has lagged (Bennis, Parikh, and Lessem 1994; Chemers 1997; Nalbandian 1994; Pearce and Conger 2003; Rost 1990; Senge 1990; Terry 1995; Terry 1993). Recent attention to the study of organizational leadership in the public service has pointed out several critical weaknesses, including the need for better articulation of leadership models in these settings and empirical testing of those models (Van Wart 2003, 225).

This study takes advantage of a very large government data set to test the utility of one of the best known theories, the "full range" leadership theory of Bernard Bass. Bass first proposed his theory in 1985 in the book Leadership and Performance Beyond Expectations. Unlike some of the other major transformational models proposed in this period that used longitudinal case studies (Bennis and Nanus 1985; Burns 1978; Tichy and Devanna 1986), Bass's model was one of the first to use survey research in a rigorous way. Bass's theory initially had six elements and was later expanded to eight by Bass himself and by others (Avolio, Waldman, and Yammarino 1991; Bass 1998; Bass and Avolio 1990) using a factor analysis based on a questionnaire called the Multifactor Leadership Questionnaire. Eight factors are not many when considering the complexity of the leadership phenomenon, yet numerous studies have supported its ability to explain leader effectiveness (Lowe, Kroeck, and Sivasubramaniam 1996). Of course, the theory's elegance also makes it prone to a number of weaknesses that will be identified later.

We examine three research questions in this study. First, how inclusive is the operational definition of leadership in the full range theory of Bernard Bass? This requires some discussion of philosophical positions about what leadership is and some detailing of Bass's theory. The major critiques of his theory are briefly reviewed.

Second, how much of an impact do Bass's leadership competencies have on follower satisfaction? The study specifies that follower satisfaction is an outcome of effective leadership. Why is it important? When controlling for the many other variables that one would expect to have an effect on satisfaction, such as pay and intrinsic enjoyment of the work, where does leadership stack up?

Third, just how important is transformational leadership compared to transactional leadership in government settings? Most analysts agree that both the instrumental elements of leadership (also called

\section{Essays on Leadership in Organizations}

Tracey Trottier is an assistant professor in the School of Public and Environmental Affairs at Indiana University South Bend. She received her doctorate in public affairs from the University of Central Florida. Her research interests are leadership in public organizations, public management, organizational behavior, and communitybased research.

E-mail: ttrottie@iusb.edu

Montgomery Van Wart is a professor and chair at California State University, San Bernardino. As a scholar, he has more than 50 publications to his credit. His book on leadership, The Dynamics of Leadership: Theory and Practice (M. E. Sharpe, 2005), was designated an Outstanding Academic Title for 2005 by Choice. His recent books on leadership include a new textbook, Leadership in Public Organizations: An Introduction, and an edited volume (with Lisa Dicke), Administrative Leadership in the Public Sector (part of the ASPA Classics series).

E-mail: mvanwart@csusb.edu

XiaoHu Wang teaches public administration courses at the University of Central Florida, specializing in performance management and financial management. He is also interested in methodological issues in public administration research. His recent book is titled Performance Analysis for Public and Nonprofit Organizations (Jones and Bartlett, forthcoming). E-mail: xwang@mail.ucf.edu 
transactional leadership or sometimes simply management) and the transformational elements are important for leadership effectiveness. A number of subtle, and a few not so subtle biases typified researchers advocating transformational variables in leadership research for nearly 20 years (Yukl 2002). When correcting for those biases and attempting to present a more balanced definition of transactional and transformational characteristics, what is the perception of their relative importance? This is a fascinating question given the generally stolid and inflexible notions that the public has of the federal service versus the much more entrepreneurial, flexible, innovative, and transformational perceptions of some observers and researchers (Bellone and Goerl 1992; Doig and Hargrove 1987; Gardner 1990; Kiel 1994; Lewis 1980; National Commission on the Public Service 1990).

The relevant literature is reviewed first, with a focus on Bass's full range leadership model, the difference that leadership makes to follower satisfaction, and the degree to which transactional leadership is more or less important than transformational leadership. The methodology section discusses how the data were collected and how Bass's definition of leadership was measured and evaluated. Next, the findings of the study are presented to answer the three key research questions raised in this study. The article concludes with implications for researchers and practitioners.

\section{Literature Review}

Leadership has existed for as long as people have interacted, and it is present in all cultures no matter what their economic or social makeup. Leadership is not only a human quality; it is found in primitive forms in many animal species, from low-level vertebrates such as chickens to higher-level primates such as gorillas and whales. Through observation and experimentation, especially conducted in the animal's own natural setting, it can be deduced that there exists a clear hierarchy or "pecking order" of leadership and that leadership grants privileges to those who have it (Bass 1990).

Although leadership is an age-old concept, it remains a complex term that researchers and scholars grapple with continuously. One of the main reasons is the extensive number of definitions for this term. It is commonly quipped that there are nearly as many definitions of leadership as there are researchers and commentators (Stogdill 1974, 7). Some researchers and commentators rely on narrow definitions for ease of communication (e.g., leadership is the act of getting other people to do what they would not otherwise willingly do) (Bennis 1959) or specific research interests (e.g., the investigation of power relationships) (French and Raven 1959).
Especially common in the 1960s was the idea that leadership is some combination of task- and peopleoriented behaviors (Blake and Mouton 1964; Hersey and Blanchard 1969). However, the definitions of most researchers have become somewhat more sophisticated and have expanded over time. As Bass and Stogdill's Handbook of Leadership explains,

The earlier definitions identified leadership as a focus of group process and movement, personality in action. The next type considered it as the art of inducing compliance. The more recent definitions conceive leadership in terms of influence relationships, power differentials, persuasion, influence on goal achievement, role differentiation, reinforcement, initiation of structure, and perceived attributions of behavior that are consistent with what the perceivers believe leadership to be. Leadership may involve all these things.

(Bass 1990, 19)

Contemporary researchers interested in the broad view of leadership and who develop operational definitions are challenged to cover many of these elements without providing excessively long, laundry-list definitions that are comprehensive but lack coherence.

\section{Bass's Full Range Leadership Model}

Bass's expanded operational definition of leadership includes eight types of leadership: laissez-faire, passive management by exception, active management by exception, contingent reward, individualized consideration, idealized influence, intellectual stimulation, and inspirational motivation (1996a). Figure 1 defines these concepts.

Bass's operational definition explicitly covers a number of the aspects discussed in the Handbook of Leadership and implicitly covers most of them. In his operational definition, leaders are implicitly the center of group processes; personality is pronounced in all of his four I's (individual consideration, idealized influence, inspirational motivation, and intellectual stimulation); influence and persuasion processes are explicit and vary from sanctions (management by exception) to rewards (contingent reward) to inspiration (inspirational motivation); goal achievement is especially explicit in his outcome interest (performance beyond expectations); initiation of structure is explicit in his transactional leadership elements (particularly management by exception and individualized consideration); and follower perceptions are implicit in the effectiveness that leaders must demonstrate in a number of styles. Although Bass does not focus on some elements, such as role differentiation or power differentials, the theory is still relatively comprehensive in 


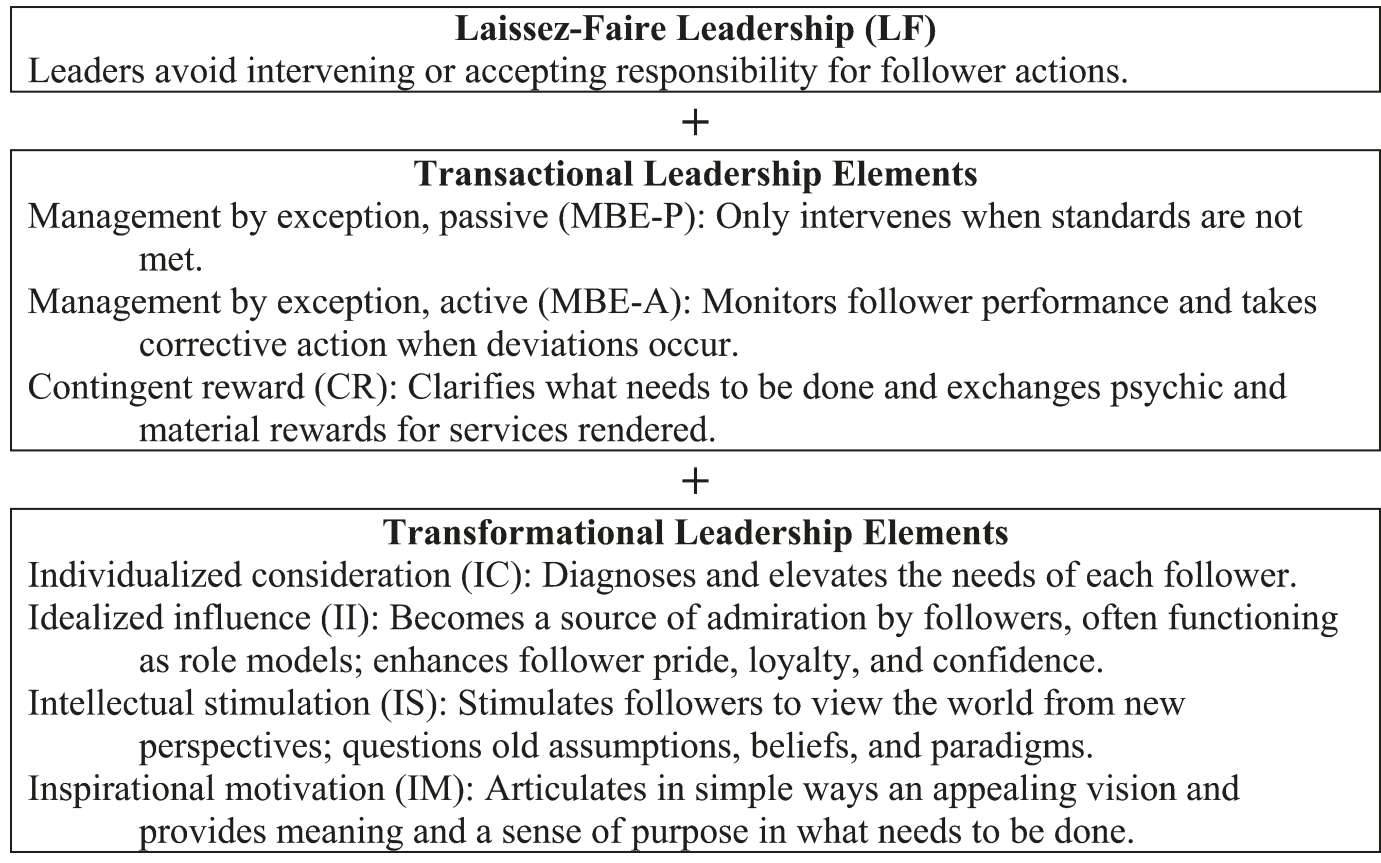

Figure 1 Bernard Bass's Revised Full Range Model of Leadership

Note: According to Bass, the priority of the elements increases substantially from top to bottom. Optimal patterns of behavior for effective leadership (relative to achieving high performance) indicate very little laissez-faire leadership, slightly more management by exception, a substantial amount of contingent reward, and an emphasis on the transformational elements (Bass 1996a).

terms of covering the major transactional and transformational elements commonly emphasized in the field.

Theories such as Bass's full range leadership model (1985), which includes transactional and transformational leadership approaches, are an important part of the leadership research. Bass's model presents researchers with a theory that can be empirically tested and provides insight into the duality that leaders face in current organizational settings.

Burns (1978) is credited with suggesting there is a dichotomy in leadership — transactional leadership and transformational leadership. Yet whereas Burns saw these as distinct leadership styles, Bass (1985, 1996a) suggested that the relationship between these styles or approaches is more complex and that both transformational and transactional leadership are necessary.

In his book Leadership and Performance beyond Expectations (1985), Bass outlines the beginnings of his theory of leadership, in which both transactional and transformational leadership are needed to enhance performance. Bass developed the full range leadership model based on his belief that transformational leadership and transactional leadership are not ends on a single continuum but rather are leadership patterns that all leaders possess and use in differing amounts. For exceptional performance, transformational leadership behaviors need to augment transactional leadership behaviors (Bass and Avolio 1993). Therefore, according to Bass, the best performance is the result of using both transactional and transformational leadership behaviors with subordinates.

The full range theory of leadership is a cumulative model (a hierarchy of relations) that works in a somewhat similar way to the motivational theories of Maslow (1954) and Herzberg (1966). Theoretically and ideally, lower-level factors - termed laissez-faire and transactional leadership-constitute the basics of the leadership function, while higher-level factors-transformational leadership—constitute advanced or high-performing leadership. Transactional elements include passive and active management by exception, in which leaders make sure that underperforming workers are corrected and developed. It also includes contingent reward, in which leaders use performance management and reward structures to motivate employees to complete their 
half of the exchange bargain optimally. Transformational elements are conceptualized by the four I's, in which followers perceive personalized support, a role model whom they can trust, a sense of vision, and stimulation to change as needed. Bass also includes laissez-faire leadership as a relatively insignificant aspect of time management, but more often a practice that is antithetical to effective leadership practice (the absence of oversight and initiative). In sum, according to Bass, good leaders avoid laissez-faire attitudes, accomplish the managerial functions of structuring the work environment and reward system as efficiently as possible (sometimes by delegation in senior positions), and spend as much time as possible on transformational aspects.

Although we adopt Bass's factor analysis as a given here, we make three modifications. First, we drop laissez-faire leadership from our analysis because it is regarded as nonleadership and therefore unnecessary for our study. Second, we combine the two types of management by exception because they are theoretically much smaller and less pronounced in comparison to other effective leadership practices (Bass 1996a, 738). They may be conceptually separate, but they are similar enough to clump together, as in the original version of the theory (Bass 1985). Third, we place individualized consideration among the transactional factors. As Yukl notes, "Although clothed in different jargon, some of the 'new' wisdom reflects themes that can be found in theories from the 1960s. For example, the importance of developing and empowering subordinates echoes the emphasis on power sharing, mutual trust, teamwork, participation, and supportive relationships by writers such as Argyris (1964), McGregor (1960), and Likert (1967)" (2002, 262). Nearly all the transactional theorists include individual consideration as one of the elements of leadership (Fiedler 1967; House and Mitchell 1974) or even place a major emphasis on it (Blake and Mouton 1964, 1965; Hersey and Blanchard 1969, 1972; House 1971) because it substantially increases satisfaction and performance in day-to-day settings and reduces turnover (Neider and Schriesheim 1988). Although individual consideration enhances transformational leadership, in which change is prominent (Kouzes and Posner 1987), we nonetheless feel that a more balanced approach can be achieved by placing it with the transactional cluster.

Despite its wide acceptance as a substantial contribution for its logical appeal, Bass's full range theory of leadership has received a substantial amount of critique, which should be kept in mind when using it for research or teaching purposes (Yukl 1999).

First, there continues to be some conceptual ambiguity about how the subtypes of leadership interact.
For example, how can one predict what will happen when transformational elements are well represented but transactional elements are virtually absent? Second, there is a bias toward executive and heroic notions of leadership, which is especially noticeable in the universal prescription for inspirational motivation or idealized influence. The follower or distributed aspects of leadership are not well articulated in Bass's model. Third, some of the roles commonly associated with leadership are not incorporated into the model (Javidian and Waldman 2003). This is most noticeable in the lack of emphasis on external roles, noted by Mintzberg (1973) as the figurehead, liaison, spokesperson, entrepreneur, and negotiator roles. Working with and developing followers may be an important role for leaders, but some people do not construe leadership so narrowly (House 1996; Hunt 1996). Fourth, like most theories emphasizing transformational elements, Bass's work weakly specifies situational variables. Although the universal approach of the theory works relatively well at the macro level by "averaging" ideal behaviors, Bass's theory fails to provide detailed explanations of concrete contexts for theory or prescriptions for teaching. Fifth, not all studies confirm Bass's factor analysis. Although most researchers agree that the transactional and transformational elements are clearly distinguished (Lowe, Kroeck, and Sivasubramaniam 1996), not all agree on the conceptual clarity of the specific transformational elements. Finally, there is a bias toward including as much in the transformational side of the equation as possible, most noticeably individualized consideration, which had long been a linchpin of transactional theories (Van Wart 2005, 349).

\section{Leadership-Follower Satisfaction Relationship}

Leadership has a variety of outcomes, and follower satisfaction is one. To make a determination about whether the revised Bass model makes a difference in the federal setting, an analysis of employee outcomes in necessary. Follower satisfaction was chosen because it could be studied with indicators from the 2002 Federal Human Capital Survey and because satisfaction is an important employee outcome. Because followers are so critical to the success of contemporary organizations (Peters 1994; Peters and Austin 1985), their satisfaction is both a vital process measure for an organization, as well as an end result in itself.

Studies have consistently found that employee satisfaction affects both short- and long-term productivity (Barnard 1938; Follett 1933; Roethlisberger and Dickson 1939), yet ironically, contemporary research has generally provided weak or inconsistent support for this intuitive contention (see Locke 1983 for a good discussion of the limitations of inferring performance from satisfaction data). Nonetheless, the 
general level of satisfaction does have an indirect but important effect on motivation by allowing workers to focus on the intrinsic enjoyment of the work (rather than strife), encouraging followers to achieve group goals, and greatly diminishing dysfunctional activity, such as work slowdowns or even sabotage (Locke 1983; Romzek 1990).

Numerous studies have linked leadership behaviors with satisfaction. Kim (2002) suggests that a leader's use of a more participative management style will result in higher levels of satisfaction among his or her employees. Jaussi and Dionne (2004) also determined that leadership plays a part in subordinate satisfaction, especially if leaders behave in unconventional ways. Some studies have asserted that "consideration" behaviors by a leader have a stronger relationship to follower satisfaction than does task or initiating-structure behavior (Judge, Piccolo, and Ilies 2004). Contingent reward behavior has also been demonstrated to have a positive relationship with subordinate satisfaction (Podsakoff, Todor, and Skov 1982). This relationship may be attributable to the fact that reward fulfillment is a basis for satisfaction, especially if the subordinate finds value in the reward (Porter and Lawler 1968).

\section{Transactional versus Transformational Leadership Debate}

As soon as transformational leadership was introduced as a major type of leadership necessary for any comprehensive conceptualization (Burns 1978), a debate began raging about the relative importance of transactional, managerial, and instrumental aspects of leadership, on one hand, and transformational, charismatic, and visionary elements, on the other (Bass 1985;

Bennis and Nanus, 1985; Conger and Kanungo 1987, 1998; Kouzes and Posner 1987; Schein 1985). In particular, the new transformational school has been eager to prove the overriding importance of transformational characteristics or even to assert that transactional elements are not a true form of leadership at all (e.g., Kotter 1990; Zaleznik 1977). Although the shrillness of the transactional versus transformational debate has subsided, the fundamental question remains interesting and varied.

First, what is the relative importance in governmental settings? (Rainey and Watson 1996). For example, Hooijberg and Choi (2001) conducted a study of private and public sector employees to see whether the generic theories of leadership in the current literature could explain differences in these sectors. They linked leadership roles comprising different behaviors from the competing values framework to see which would have a greater impact on perceived effectiveness in different sectors. Their research indicates that monitoring and facilitating roles have more of an impact on perceived leadership effectiveness in the public sector. Second, does transformational leadership seem to make as much of a difference in the public sector as it does in the private sector? Third, does the level of transformational leadership desired by followers vary over time as circumstances shift such as demand for organizational change from the environment? This re-

search seeks to provide one assessment of the first question, some comparisons for the second question, and, related to the third, a benchmark for future research.

Aspects of transformational leadership have long been recognized as important in public sector administrative settings (Jenkins 1947; Selznick 1957; Stone 1945, 1981; Corson and Paul 1966), even they are though poorly articulated in formal leadership theory. Transformational leadership theory evolved rapidly in the late 1970s and 1980s because the organizational universe shifted dramatically, elevating transformation and thus requiring a new culture of dynamism rather than stability. As Rosabeth Moss Kanter notes succinctly, "change requires leadership" (1983, 125). Certainly, the shift in the global economy profoundly affected many of the Westminster governments (e.g., New Zealand and Great Britain) in the 1980s with a wave of "New Public Management" (Hood 1991) and affected the U.S. public sector as dramatically in the 1990s (Van Wart and Berman 1999).

As previously discussed, the transformational school of leadership has claimed elements of what has long been a part of the transactional literature: consideration and basic follower support. This study places follower support back into transactional leadership because the augmentation effect that Bass asserts theoretically allows for this dual role. Good contingent reward management should be in place in order to build high-performance systems utilizing transformational leadership competencies.

\section{Methodology}

\section{Data}

To answer the research questions in this study, an analysis of federal survey data was conducted. Data for this analysis were obtained from the U.S. Office of Personnel Management (OPM). In 2002, the OPM conducted the Federal Human Capital Survey "to assess the presence and extent of conditions that characterize high performance organizations" $(2003,2)$. The survey 
is considered the most sizable survey that has ever been completed of federal government employees to date (OPM 2003). It was electronically distributed to a stratified random sample of federal government employees in federal agencies between May and August 2002. The stratification was based on employees' agencies and positions (executives, managers/supervisors, and nonsupervisors/team leaders). The survey was distributed to 208,424 employees who worked in agencies within the executive branch of the federal government, both in the United States and abroad. A 51 percent response rate was realized, with 106,742 surveys being returned (OPM 2003). Of those that were returned, 100,657 were considered usable for the analysis in this study. The data from these surveys were obtained and converted to an SPSS file for analysis.

In the survey, questions covered a wide array of issues, including strategic alignment, strategic competencies (talent), leadership, performance culture, learning (knowledge management), personal experiences, job satisfaction, compensation and benefits, and familyfriendly flexibilities. Demographic items were also asked of the survey participants, including the agency the respondent worked for, the agency subunit, supervisory status, gender, and race.

In the survey, participants were given an identification and password and asked to log in to the survey Web site. Accommodations were made for those employees who needed or preferred paper versions of the survey and for employees with disabilities. In addition, participants were protected under Public Law 93-579, the Privacy Act of 1974, which makes the giving of any personal information voluntary. Participants were also notified that individual responses would be confidential and that the agencies they worked for would only receive aggregate data, which would not allow for the identification of specific responses (OPM 2002).

\section{Measurement}

The Federal Human Capital Survey addressed organizational performance, leadership, and employee satisfaction. It included 118 individual question items, many of which were used to measure the concepts in this study. The following discussion establishes the operational definitions of the variables in the study and the specific measures that were used.

The study measured six leadership dimensions: management by exception, contingent reward, individualized consideration, idealized influence, inspirational motivation, and intellectual stimulation. It also measured transactional and transformational leadership behaviors, which were set forth by Bass and updated by Bass and associates (Avolio, Waldman, and Yammarino, 1991; Bass 1985, 1996b, 1998; Bass and Avolio 1990). These are combinations of the foregoing six leadership dimensions.
Table 1 lists the 24 survey items used to measure these leadership behaviors in this study. Several criteria were used in selecting these items. First, the leadership literature and Bass's full range leadership model provided the guidelines for item selection. For example, Bass's concept of management by exception was measured by responses to the statement, "Information collected on my work unit's performance is used to improve my work unit's performance." When using this type of leadership behavior, leaders "intervene with negative feedback or disciplinary action when employee performance falls too far below standards" (Bass 1985, 136). Thus, the collection of performance data can be used to determine when to intervene. Similarly, the survey item "In my organization, leaders generate high levels of motivation and commitment in the workforce" was used to measure inspirational motivation. Bass proposes that inspirational leadership occurs when "leaders behave in ways that motivate and inspire those around them by providing meaning and challenge to their followers' work" $(1985,5)$.

Second, the items selected should be relatively reliable. Multiple items selected to measure the same concept should have internal consistency-they should be at least associated. Association-based Cronbach's alpha was used to test reliability of measures. The alpha values are also shown in table 1 . An alpha value above 0.700 is preferred, and all the alpha values in this study exceed this except for the measure of management by exception, which has a value of 0.661 . However, alpha values lower than 0.700 have often been used in the literature to measure concepts of managerial behaviors not frequently measured before (Dangayach and Deshmukh 2005; Nunnally 1978). Moreover, the use of the measure was necessary because the selection of items was limited by the survey and there were no alternative measures to replace it (Berman 2001).

Composite indices were created in the study. The indices for the six leadership dimensions used (management by exception, contingent reward, individualized consideration, idealized influence, inspiration motivation, and intellectual stimulation) were created by combining the relevant indicators shown in table 1 and dividing by the total number of indicators for that index. The transactional leadership index was created by combining all the indicators of management-by-exception, contingent reward, and individualized consideration and dividing by the total number of indicators. The transformational index was created by combining all the indicators of idealized influence, inspirational motivation, and intellectual stimulation and dividing by the total number of indicators. The combined leadership index was created by combing all the indicators of the six separate leadership dimensions and dividing by the total number of indicators. 


\begin{tabular}{|c|c|c|}
\hline Measurements & Mean & SD \\
\hline Management by Exception (Cronbach's alpha = .661) & 3.33 & 0.825 \\
\hline Information collected on my work unit's performance is used to improve my work unit's performance. & 3.44 & 1.105 \\
\hline In my work unit, steps are taken to deal with a poor performer who cannot or will not improve. & 2.75 & 1.181 \\
\hline I have enough information to do my job well. & 3.78 & 0.896 \\
\hline Contingent Reward (Cronbach's alpha $=.913)$ & 3.35 & 0.947 \\
\hline Selections for promotions in my work unit are based on merit. & 3.12 & 1.254 \\
\hline Awards in my work unit depend on how well employees perform their jobs. & 3.29 & 1.209 \\
\hline High-performing employees in my work unit are recognized or rewarded on a timely basis. & 3.21 & 1.212 \\
\hline Employees are rewarded for providing high quality products and services to customers. & 3.30 & 1.162 \\
\hline My performance appraisal is a fair reflection of my performance. & 3.67 & 1.082 \\
\hline Discussions with my supervisor/team-leader about my performance are worthwhile. & 3.52 & 1.083 \\
\hline How satisfied are you with the recognition you receive for doing a good job? & 3.30 & 1.147 \\
\hline Individualized Consideration (Cronbach's alpha = .905) & 3.63 & 0.869 \\
\hline My supervisor supports my need to balance work and family issues. & 4.04 & 1.017 \\
\hline My talents are used well in the workplace. & 3.54 & 1.205 \\
\hline $\begin{array}{l}\text { Supervisors/team leaders in my work unit provide employee(s) with the opportunities to demonstrate } \\
\text { their leadership skills. }\end{array}$ & 3.53 & 1.076 \\
\hline Supervisors/team leaders in my work unit encourage my development at work. & 3.57 & 1.095 \\
\hline I am given a real opportunity to improve my skills in my organization. & 3.56 & 1.033 \\
\hline My job makes good use of my skills and abilities. & 3.64 & 1.099 \\
\hline How satisfied are you with your involvement in decisions that affect your work? & 3.47 & 1.092 \\
\hline Idealized Influence (Cronbach's alpha = .813) & 3.36 & 1.074 \\
\hline My organization's leaders maintain high standards of honesty and integrity. & 3.41 & 1.191 \\
\hline Complaints, disputes or grievances are resolved fairly in my work unit. & 3.31 & 1.138 \\
\hline Inspirational Motivation (Cronbach's alpha $=.847$ ) & 3.03 & 1.121 \\
\hline In my organization, leaders generate high levels of motivation and commitment in the workforce. & 2.99 & 1.209 \\
\hline Employees have a feeling of personal empowerment and ownership of work processes. & 3.06 & 1.197 \\
\hline Intellectual Stimulation (Cronbach's alpha $=.815$ ) & 3.35 & 0.960 \\
\hline Supervisors/team leaders are receptive to change. & 3.29 & 1.091 \\
\hline Creativity and innovation are rewarded. & 3.19 & 1.166 \\
\hline I feel encouraged to come up with new and better ways of doing things. & 3.57 & 1.108 \\
\hline $\begin{array}{l}\text { Transactional Leadership (Cronbach's alpha = .947) } \\
\text { A composite of all the indicators included in Management by Exception, Contingent Reward, and } \\
\text { Individualized Consideration. }\end{array}$ & 3.47 & 0.824 \\
\hline $\begin{array}{l}\text { Transformational Leadership (Cronbach's alpha }=.917) \\
\text { A composite of all the indicators included in Idealized Influence, Inspirational Motivation, and } \\
\text { Intellectual Stimulation. }\end{array}$ & 3.27 & 0.950 \\
\hline $\begin{array}{l}\text { Combined Leadership (Cronbach's alpha }=.966 \text { ) } \\
\text { A composite of all the indicators included in Management by Exception, Contingent Reward, } \\
\text { Individualized Consideration, Idealized Influence, Inspirational Motivation, and Intellectual Stimulation. }\end{array}$ & 3.42 & 0.846 \\
\hline
\end{tabular}

Note: All items are measured on a five-point scale ranging from 1 = "strongly disagree" to $5=$ "strongly agree," except the last item in "Contingent Reward" and the last item in "Individualized Consideration," which are measured on a five-point scale ranging from $1=$ "very dissatisfied" to $5=$ "very satisfied."

The study also measured perceived leadership effectiveness and follower satisfaction. Perceived leadership effectiveness was indicated by an overall assessment of leadership results perceived by the employees. Two items were used to measure perceived leadership effectiveness and create a composite index: "I hold my organization's leaders in high regard" and "Overall, how good a job do you feel is being done by your immediate supervisor/team leader?" A test of internal reliability showed that the index variable was relatively reliable to measure leadership effectiveness $($ Cronbach's alpha $=0.731)$.

Follower satisfaction is an outcome of leadership. In this study, it was operationalized to include three dimensions of a follower's satisfaction: satisfaction with the job, satisfaction with the organization, and recom- mendation for others. Three survey items were used in measurement: "Considering everything, how satisfied are you with your job?" "Considering everything, how would you rate your overall satisfaction in your organization at the present time?" and "I recommend my organization as a good place to work." A composite index including all three items was created to measure follower satisfaction. The index had a relatively high level of internal reliability (Cronbach's alpha $=0.881$ ).

In addition, several demographic and other organizational variables were measured and controlled through a multivariate statistical model examining the impact of leadership on satisfaction. These control variables included the gender and ethnicity of the responder, the supervisory status of the responder, and the respondent's satisfaction with other organizational 
dimensions that influence follower satisfaction, such as pay, benefits, career path, personal fulfillment of their job, the physical conditions, organizational training, workplace flexibilities, coworkers, and organizational communications.

\section{Findings}

Before empirically examining the comprehensiveness of the Bass theory or its predictability in terms of follower satisfaction, it is interesting to see just how well federal managers are perceived to perform in different leadership competencies. For example, on average, do federal workers perceive their leaders to be stronger at transactional or transformational competencies?

First, the descriptive statistics in table 1 show that federal managers are perceived to be about average3.0 to 3.6 - or slightly above average on a strictly numerical basis. One competency seems to stand out as the best: individual consideration. Given the culture of emphasizing "individual development plans" and management by objectives in federal training programs for many decades, this is not surprising. However, federal managers are weakest at inspirational motivation-generating high levels of motivation and feelings of empowerment and ownership of work processes. Given nearly fifteen years of total quality management and reinventing government initiatives, this is a bit surprising. Nonetheless, inspirational motivation is not easy to achieve for any bureaucratic leader
(Bennis and Nanus 1985) and the need for compliance and rule-based mentality in much of the federal system would likely diminish this capacity (Howard 1994). Before we get to the question of what is most important for leadership effectiveness or follower satisfaction from a theoretical perspective, based on the data, we can definitely say that federal managers excel at transactional leadership (3.47) over transformational leadership (3.27) competencies. A paired sample $t$-test shows that the difference is statistically significant at the .01 level $(t=135.97, p<.0005)$ with a sample of 82,703 .

\section{How Comprehensive Is Bass's Full Range Theory of Leadership in a Federal Setting?}

Despite some of the critiques of the full range theory above, the findings suggest that the amount of perceived leadership effectiveness captured by Bass's six variables is quite high—about 70 percent_when comparing his mid-level constructs to an overarching assessment of leadership effectiveness. The proportion of explained variances $\left(R^{2}\right)$ for the transactional, transformational, and combined leadership factors can be found in figure 2. Although not as high as Bass himself has asserted (Bass 1985), the finding compares favorably with other popular frameworks such as Kouzes and Posner's (1987) 10 leadership practices using a critical incident methodology. The results are consistent with other empirical researchers who have found that charismatic (Javidian and Waldman 2003) or transformational elements (Hennessey 1998) must

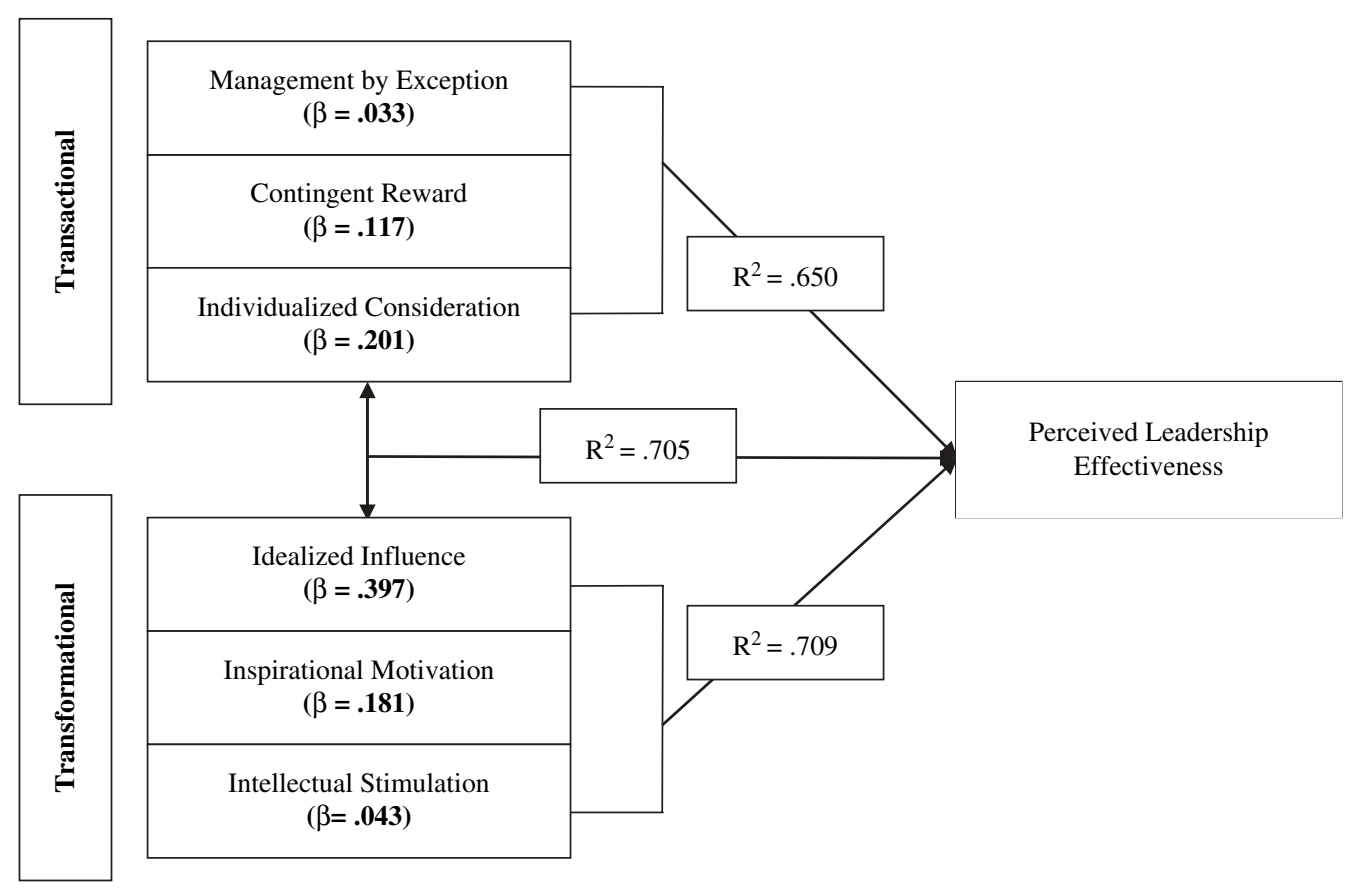

Figure 2 Relationship of Leadership Behaviors to Perceived Leadership Effectiveness

* Betas are obtained from the model that includes six leadership behavior dimensions as individual variables and controls for supervisory status only. $R^{2}$ values are from models that include the individual leadership behavior dimensions (transactional, transformational, and combined leadership) and controls for supervisory status only. 
be included in a comprehensive operational definition of leadership in public sector settings. Also included in the figure are the standardized coefficients (betas) for each of the six factors, which indicate the relative ranking that followers assign to each. Idealized influence is ranked first, individualized consideration second, inspirational motivation third, and contingent reward fourth. The low beta and ranking of intellectual stimulation (.043 and fifth place) was not anticipated and will be discussed later; the last-place ranking of management by exception is anticipated by Bass's theory.

A significant amount of the variance of leadership effectiveness is not explained, and it may be interesting and useful to speculate about what is missing from Bass's operational definition. First, diligence, perseverance, and efficient management may be poorly captured by the six categories (Howard and Bray 1988; Stogdill 1974). As Kouzes and Posner opine, "getting extraordinary things done in organizations is hard work" (1987, 239). Second, technical competence (OPM 1997, 1999; Rankin 2001) and generic management competencies such as human resource management and information technology (Neider and Schriesheim 1988; OPM 1997, 1999) are not incorporated in this study. Many studies have demonstrated that although these characteristics rarely lead to perceptions of great leadership, their absence in leaders can be problematic in many instances (McCall, Lombardo, and Morrison 1988). Third, style range and versatility are poorly captured by this universal model. It is well known that transformational leaders may flourish in one setting, only to flounder in another as the rise and fall of corporate executives amply testifies; this has also been documented in the public sector (Roberts and Bradley 1988). Having demonstrated that Bass's definition holds up fairly well in a federal setting as a macro-level operational definition, we now explore the effect of leadership on satisfaction.

\section{How Much Effect Does the Full Range Leadership Model Have in a Federal Setting?}

It should be noted that many factors affect follower satisfaction, in addition to leader effectiveness. Classic variables in this regard are managerial status, pay, benefits, career path, personal fulfillment of the job, physical conditions, training, workplace satisfaction, supervisory status, gender of respondent, ethnicity, and coworkers. Therefore, all of these variables, along with the leadership variables, were included in a multiple regression model to examine the impact of leadership on follower satisfaction. Tests of model assumption were conducted and no consequential violation of linearity and heteroskedasticity was detected. The model has a slight sign of multicollinearity; the six leadership dimensions are associated, as expected. Nevertheless, the test of tolerance statistics detects no serious violation of model assumption of multicollinearity (Pallant 2005).

Table 2 presents statistics that specify the impact of individual variables on follower satisfaction. All variables in the model, except benefits, are statistically significant at the $\leq .001$ level. More than 70 percent of variance of follower satisfaction is explained by the model that includes leadership and other variables, suggesting the model is specified correctly and concepts in the model are measured well. To examine relative impact of these individual variables on follower satisfaction, standardized coefficients are presented in a descending order.

This analysis highlights the prospective role of leaders in maintaining follower satisfaction. Three factors are virtually tied for second place: leader motivation and empowerment, individual consideration by leaders, and the ability to trust leaders. Leadership competencies that are more instrumental, such as contingent reward (matching rewards and recognition to performance) and managing by exception (e.g., getting feedback on job performance and disciplining poor performers), have a relatively low ranking and effect on satisfaction of followers. The change orientation of leaders (intellectual stimulation) actually has a slightly negative correlation, which is not surprising given the unsettling nature of change, even when it is well done.

is well done.

\section{How Important Is} Transactional Compared to Transformational Leadership in the Federal Setting?

The question about the relative importance of transactional and transformational leadership can be answered in several ways. First, respondents ranked transformational leadership variables as slightly more important in terms of their overarching concept of leadership effectiveness (see figure 2). The three transformational variables together accounted for 70.9 percent of the variance of perceived leadership effectiveness, while transactional variables accounted for 65 percent. This slight edge is maintained when the relationship is examined in the case of follower satisfaction (see figure 3). The three transactional variables accounted for 70.7 percent, while the transformational variables accounted for 72.5 percent. The importance of these data is not which type of leadership has the edge, however, but that transformational leadership has such a large role in 
Table 2 Regression Model of Follower Satisfaction in Descending Order of Standardized Coefficients

\begin{tabular}{lcc}
\hline $\begin{array}{l}\text { All Variables Affecting } \\
\text { Follower Satisfaction } \\
\text { (in descending order, }\end{array}$ & $\begin{array}{c}\text { Unstandardized } \\
\text { Coefficients }\end{array}$ & $\begin{array}{c}\text { Standardized } \\
\text { Coefficients }\end{array}$ \\
\hline disregarding sign) & $.277^{* *}$ & .253 \\
\hline Personal fulfillment of job & $.152^{* *}$ & .172 \\
Inspirational motivation & $.194^{* *}$ & .170 \\
Individualized consideration & $.157^{* *}$ & .170 \\
Idealized influence & $.083^{* *}$ & .097 \\
Career path & $.070^{* *}$ & .082 \\
Communication & $.067^{* *}$ & .067 \\
Pay & $.055^{* *}$ & .049 \\
Coworkers & $-.094^{* *}$ & -.046 \\
Supervisor/manager status & $-.154^{* *}$ & -.027 \\
Executive status & $.020^{* *}$ & .023 \\
Physical conditions & $.023^{* *}$ & .022 \\
Contingent reward & $.022^{* *}$ & .018 \\
Management by exception & $.021^{* *}$ & .018 \\
Workplace flexibilities & $.015^{* *}$ & .015 \\
Organizational training & $-.013^{* *}$ & -.012 \\
Intellectual stimulation & $-.016^{* *}$ & -.008 \\
Gender of respondent & $-.016^{* *}$ & -.007 \\
Ethnicity of respondent & .004 & .004 \\
Benefits & .736 & \\
Adjusted $R^{2}$ & & \\
\hline
\end{tabular}

** Significant at the $\leq .001$ level.

Leadership factors in italics.

the perceptions of federal workers after correcting some of the biases of transformational researchers by placing individual consideration in the transactional cluster. However, as table 1 indicates, federal workers actually rank their leaders higher in transactional leadership factors (3.47) than transformational factors (3.27).
The third way to look at the transactional versus transformational issue is by each of the major variables studied in this case. Table 3 summarizes the relative ranking of individual factors using the mean averages in table 1 and the standardized coefficients in figure 2 and table 2. In both followers' perceptions of what it takes to be an effective leader, or what it takes to enhance follower satisfaction, three leadership factors stand out: individualized consideration, idealized influence, and inspirational motivation. Though these three factors are virtually tied in terms of contributing to follower satisfaction, the ranking is quite clear in terms of effectiveness. First and foremost, effective leaders must be trustworthy, followed by being considerate of followers' individual needs and talents, and finally being able to instill motivational enthusiasm and a sense of empowerment. While it can be seen in table 3 that federal managers are, in fact, strong in the first two elements, they are relatively weak in instilling enthusiasm and a sense of empowerment. Federal managers tend to be slightly stronger at the other transactional factors-management by exception and contingent reward - than followers indicate is important for effectiveness or satisfaction. The same is true for the one low-ranked transformational item, intellectual stimulation.

Thus, when examining Bass's six leadership factors from three perspectives, we see that neither transactional nor transformational factors clearly predominate, although transformational factors have an edge in followers' perceptions of importance. If

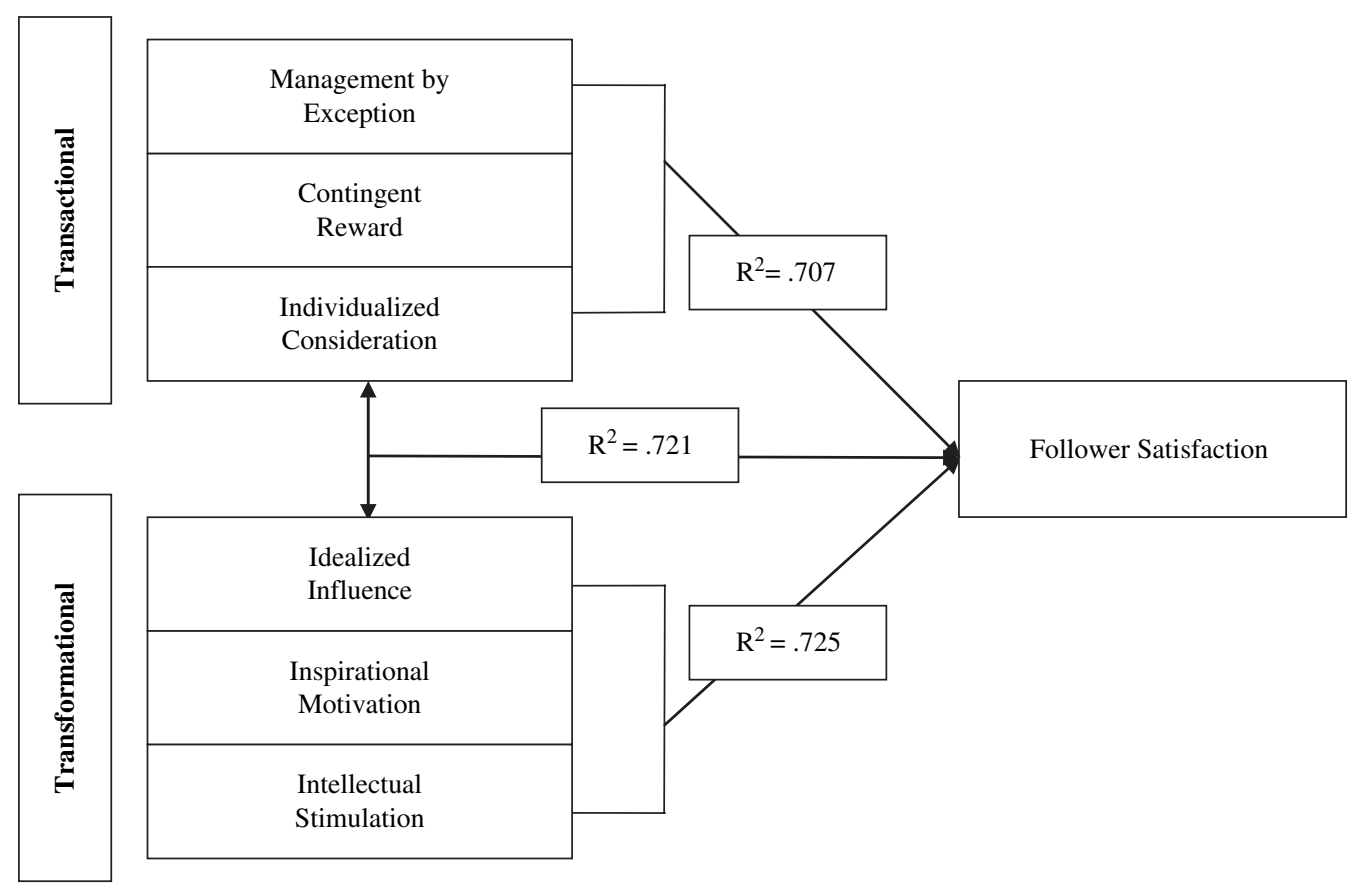

Figure 3 Relationship of Leadership Behaviors to Follower Satisfaction

* Controls for gender, ethnicity, supervisory status, pay satisfaction, benefit satisfaction, career path satisfaction, personal fulfillment of the job, physical work conditions, organizational training, coworkers, and communication. These regression models are based on three composite leadership dimensions: transactional, transformational, and combined leadership behaviors. 
Table 3 Comparison of the Factor Ranking of Leadership Behaviors

\begin{tabular}{lccc}
\hline Leadership Factor & $\begin{array}{c}\text { Ranking of } \\
\text { the Mean }\end{array}$ & $\begin{array}{c}\text { Ranking of Standardized Coefficient } \\
\text { for Leadership Effectiveness }\end{array}$ & $\begin{array}{c}\text { Ranking of Standardized Coefficient } \\
\text { for Follower Satisfaction }\end{array}$ \\
\hline Management by exception & 5 & 6 & 5 \\
Contingent reward & 3 & 4 & 4 \\
Individualized consideration & 1 & 2 & $1 / 2 / 3^{*}$ \\
Idealized influence & 2 & 3 & $1 / 2 / 3^{*}$ \\
Inspirational motivation & 6 & 5 & 6 \\
Intellectual stimulation & 4 & $1 / 2 / 3^{*}$ & \\
\hline
\end{tabular}

* Inspirational motivation was .002 greater than individualized consideration and idealized influence. Ranking of standardized coefficients is based on their signs and directions.

individualized consideration were reunited under the rubric of transformational leadership, the scale would tip heavily in that direction. Contingent reward is an important factor in terms of perceived leadership effectiveness, but it is less so in terms of follower satisfaction. Management by exception is a significant but relatively small factor, as one would expect in terms of shaping effectiveness and satisfaction, but surprisingly, intellectual stimulation is very low. Followers do not perceive leaders' receptivity to change and the rewarding of creativity and innovation to be major determinants of change; indeed, a change orientation actually has a slightly negative correlation with satisfaction. Although followers may perceive this to be quite low in their priorities, superiors and the public's proxies (e.g., elected executives and legislators) might be likely to place it very high, but this is beyond the scope of the study.

\section{Discussion and Conclusion}

Despite an enormous amount of discussion about leadership in public agencies, there has been relatively little broad-scale empirical analysis. This study uses the data from the 2002 Federal Human Capital Survey to assess three major leadership questions empirically. How well does the operational definition for Bass's well-known full range theory hold up, how much of an impact does leadership have on follower satisfaction, and can one get a sense of the relative importance of transactional and transformational leadership behaviors?

Descriptively, federal managers range from 3.0 to 3.6 on a five-point scale when evaluating them using Bass's six leadership competencies or factors. The transactional competencies are management by exception, contingent reward, and individualized consideration (this last factor being placed with transactional competencies for this study). The transformational competencies are idealized influence, inspirational motivation, and intellectual stimulation. In terms of specific performance, then, federal managers are generally about average on four of these factorseach approximately 3.3. Federal managers did substantially better on individualized consideration (3.6) and substantially poorer on intellectual stimulation (3.0).
One method of testing Bass's theory was to use followers' conceptualization of leader effectiveness as a dependent variable and to examine both the variance explained and the relative weighting of the factors. Bass's definition holds up very well in terms of leadership effectiveness from followers' perceptions, accounting for more than 70 percent of the variance. Idealized influence is the most important factor, but inspirational motivation, individualized consideration, and contingent reward are also important (in that order). As predicted by Bass's theory, management by exception has a relatively modest impact, but contrary to his theory, intellectual stimulation has a miniscule impact rather than a substantial one.

How significant of an effect does leadership have to follower satisfaction? It has an enormous effect. The six leadership factors are statistically significant in a model predicting follower satisfaction, and three of the six leadership factors exceed standard satisfaction areas such as pay, promotion, coworkers, and working conditions, and only personal fulfillment of the job exceeds them. This is in agreement with findings of Buckingham and Coffman (1999; see also Kim 2002) but at some variance with the retention/turnover literature, which does not generally highlight the importance of leadership to this degree (e.g., Fottler, Shewchuk, and O'Connor 1998). This may be attributable to the fact that these studies only examine the impact of the employee-supervisor relationship, not the numerous indirect influences that leadership has on the climate, working environment, and overall culture.

The study also examines the transactional or transformational leadership debate in government settings, which are traditionally more constrained, even in an increasingly results-oriented and entrepreneurial environment. On average, transformational leadership is slightly more important in terms of both perceptions of leader effectiveness and follower satisfaction in the federal case, despite the substantial conceptual expansion of transactional leadership for this study. Effective public sector management has always depended to some degree on transformational leadership behaviors (e.g., Selznick 1957), but it seems likely that these characteristics have been 
emphasized since the 1990s with downsizing, pressure for results, devolution of authority, and increased use of market strategies (e.g., weakening of civil service rules). However, on average, federal managers are evaluated as better transactional leaders, and fall down noticeably in one key transformational area: inspirational motivation.

Additional research can test and contextualize these findings. Examples of such research include follow-up studies with future OPM data to study longitudinal trends, broad-scale examination of the nature and effects of leadership in state and local governments, and studies that focus on some of the major situational aspects of leadership (hierarchy, organizational type, degree of organizational stress, gender, culture) in public settings.

In sum, we can say with confidence that Bass's blended transactional and transformational model of leadership does capture well the major elements of what followers perceive to be important and that very good leadership seems to depend even more on transformational elements than transactional, even when individual consideration is placed on the transactional side of the model. The answer to the question about whether leadership is significant in government organizations, using the follower satisfaction affect as a proxy, is a resounding yes. In practical terms, then, the selection and grooming of leaders has room for substantial improvement in the federal case. Leaders need not only the traditional technical and managerial skills of the past but also well-honed transformational competencies emphasizing mission articulation, vision, and inspirational motivation. Although revised OPM competency models (1999) have reflected an increased transformational emphasis, descriptive empirical data (as well as our theoretical analysis) reveals that more needs to be done by federal agencies in this regard.

\section{References}

Argyris, Chris. 1964. Integrating the Individual and the Organization. New York: Wiley.

Avolio, Bruce J., David A. Waldman, and Francis J.

Yammarino. 1991. Leading in the 1990s: The Four

I's of Transformational Leadership. Journal of

European Industrial Training 15(4): 9-16.

Barnard, Chester I. 1938. The Functions of the

Executive. Cambridge, MA: Harvard University

Press.

Bass, Bernard M. 1985. Leadership and Performance

Beyond Expectations. New York: Free Press.

-1990. Bass and Stogdill's Handbook of

Leadership: Theory, Research, and Managerial

Applications. New York: Free Press.

- 1996a. Is There Universality in the Full

Range Model of Leadership? International Journal

of Public Administration 19(6): 731-61. 1996b. A New Paradigm of Leadership: An

Inquiry into Transformational Leadership.

Alexandra, VA: U.S. Army Research Institute for the Behavioral and Social Sciences.

1998. Transformational Leadership: Industrial,

Military, and Educational Impact. Mahwah, NJ:

Lawrence Erlbaum.

Bass, Bernard M., and Bruce J. Avolio. 1990. The Implications of Transactional and Transformational Leadership for Individual, Team, and Organizational Development. In Research in Organizational Change and Development, edited by W. Pasmore and R. W. Woodman, vol. 4, 231-72. Greenwich, CT: JAI Press.

. 1993. Transformational Leadership: A

Response to Critiques. In Leadership Theory and Research: Perspectives and Directions, edited by Martin M. Chemers and Roya Ayman, 49-80. San Diego, CA: Academic Press.

Bellone, Carl J., and George Frederick Goerl. 1992. Reconciling Public Entrepreneurship and Democracy. Public Administration Review 52(2): 130-34.

Bennis, Warren. 1959. Leadership Theory and Administrative Behavior: The Problems of Authority. Administrative Science Quarterly 8(2): 125-65.

Bennis, Warren, and Burt Nanus. 1985. Leaders: Strategies for Taking Charge. New York: Harper \& Row.

Bennis, Warren, Jagdish Parikh, and Ronnie Lessem. 1994. Beyond Leadership: Balancing Economics, Ethics, and Ecology. Cambridge, MA: Blackwell Business.

Berman, Evan M. 2001. Essential Statistics for Public Managers and Policy Analysts. Washington, DC: CQ Press.

Blake, Robert R., and Jane S. Mouton. 1964. The Managerial Grid: Key Orientations for Achieving Production through People. Houston, TX: Gulf

_. 1965. A 9, 9 Approach for Increasing Organizational Productivity. In Personal and Organizational Change through Group Methods, edited by Edgar H. Schein and Warren G. Bennis, 165-83. New York: Wiley.

Buckingham, Marcus, and Curt Coffman. 1999. First, Break All the Rules: What the World's Greatest Managers Do Differently. New York: Simon \& Schuster.

Burns, James MacGregor. 1978. Leadership. New York: Harper \& Row.

Chemers, Martin M. 1997. An Integrative Theory of Leadership. Mahwah, NJ: Lawrence Erlbaum.

Conger, Jay A., and Rabindra N. Kanungo. 1987. Toward a Behavioral Theory of Charismatic Leadership in Organizational Settings. Academy of Management Review 12(4): 637-47. 
1998. Charismatic Leadership in

Organizations. Thousand Oaks, CA: Sage

Publications.

Corson, John J., and R. Shale Paul. 1966. Men Near the Top: Filling Key Posts in the Federal Service. Baltimore: Johns Hopkins University Press.

Dangayach, G. S., and S. G. Deshmukh. 2005. Advanced Manufacturing Technology Implementation: Evidence from Indian Small and Medium Enterprises (SMEs). Journal of Manufacturing Technology Management 16(5): 483-96.

Doig, Jameson W., and Erwin C. Hargrove, eds. 1987. Leadership and Innovation: A Biographical Perspective on Entrepreneurs in Government. Baltimore: Johns Hopkins University Press.

Fiedler, Fred E. 1967. A Theory of Leadership Effectiveness. New York: McGraw-Hill.

Follett, Mary Parker. 1933. Mary Parker FollettProphet of Management: A Celebration of Writings from the 1920s. Ed. Pauline Graham. Boston: Harvard Business School Press, 1996.

Fottler, Myron D., Richard M. Shewchuk, and Stephen J. O’Connor. 1998. Relative Importance of Job Attributes for the Recruitment and Retention Decisions of Health Care Executives. International Journal of Organizational Theory and Behavior 1(2): 223-47.

French, John, and Bertram H. Raven. 1959. The Bases of Social Power. In Studies in Social Power, edited by Dorwin Cartwright, 150-67. Ann Arbor: University of Michigan, Institute for Social Research.

Gardner, John W. 1990. On Leadership. New York: Free Press.

Hennessey, J. Thomas. 1998. Reinventing Government: Does Leadership Make the Difference? Public Administration Review 58(6): 522-32.

Hersey, Paul, and Kenneth H. Blanchard. 1969. Life Cycle Theory of Leadership. Training and Development Journal 23(1): 26-34.

. 1972. The Management of Change. Training and Development Journal 26(2): 20-24.

Herzberg, Frederick. 1966. Work and the Nature of Man. Cleveland, OH: World Publishing.

Hood, Christopher. 1991. A Public Management for All Seasons? Public Administration 69(1): 3-19.

Hooijberg, Robert, and Jaepil Choi. 2001. The Impact of Organizational Characteristics on Leadership Effectiveness Models: An Examination of Leadership in a Private and a Public Sector Organization. Administration \& Society 33(4): 403-31.

House, Robert J. 1971. A Path-Goal Theory of Leader Effectiveness. Administrative Science Quarterly 16(3): 321-28.
1996. Path-Goal Theory of Leadership: Lessons, Legacy, and a Reformulated Theory. Leadership Quarterly 7(3): 323-52.

House, Robert J., and Terence. R. Mitchell. 1974. Path-Goal Theory of Leadership. Journal of Contemporary Business 3: 81-98.

Howard, Ann, and Douglas W. Bray. 1988. Managerial Lives in Transition: Advancing Age and Changing Times. New York: Guilford Press.

Howard, Philip K. 1994. The Death of Common Sense: How Law Is Suffocating America. New York: Random House.

Hunt, James G. 1996. Leadership: A New Synthesis. Newbury Park, CA: Sage Publications.

Jaussi, Kimberly S., and Shelley D. Dionne. 2004. Unconventional Leader Behavior, Subordinate Satisfaction, Effort, and Perception of Leader Effectiveness. Journal of Leadership and Organizational Studies 10(3): 15-26.

Javidian, Mansour, and David A. Waldman. 2003. Exploring Charismatic Leadership in the Public Sector: Measurement and Consequences. Public Administration Review 63(2): 229-42.

Jenkins, William O. 1947. A Review of Leadership Studies with Particular Reference to Military Problems. Psychological Bulletin 44: 54-79.

Judge, Timothy A., Ronald F. Piccolo, and Remus Ilies. 2004. The Forgotten Ones? The Validity of Consideration and Initiating Structure in Leadership Research. Journal of Applied Psychology 89(1): 36-51.

Kanter, Rosabeth Moss. 1983. The Change Masters. New York: Simon \& Schuster.

Kiel, L. Douglas. 1994. Managing Chaos and Complexity in Government: A New Paradigm for Managing Change, Innovation, and Organizational Renewal. San Francisco: Jossey-Bass.

Kim, Soonhee. 2002. Participative Management and Job Satisfaction: Lessons for Management Leadership. Public Administration Review 62(2): 231-41.

Kotter, John P. 1990. A Force for Change: How Leadership Differs from Management. New York: Free Press.

Kouzes, James M., and Barry Z. Posner. 1987. The Leadership Challenge: How to Get Extraordinary Things Done in Organizations. San Francisco: Jossey-Bass.

Lewis, Eugene. 1980. Public Entrepreneurship: Toward a Theory of Bureaucratic Political Power. Bloomington: Indiana University Press.

Likert, Rensis. 1967. The Human Organization: Its Management and Value. New York: McGraw-Hill.

Locke, Edwin A. 1983. The Nature and Causes of Job Satisfaction. In Handbook of Industrial and Organizational Psychology, edited by Marvin D. Dunnette, 1297-1349. New York: Wiley. 
Lowe, Kevin B., K. Galen Kroeck, and Nagaraj

Sivasubramaniam. 1996. Effectiveness of

Correlates of Transformational and Transactional

Leadership. Leadership Quarterly 7(3):

385-425.

Maslow, Abraham. 1954. Motivation and Personality.

New York: Harper.

McCall, Morgan W., Jr., Michael M.. Lombardo, and Ann M. Morrison. 1988. The Lessons of Experience: How Successful Executives Develop on the Job. Lexington, MA: Lexington Books.

McGregor, Douglas. 1960. The Human Side of Enterprise. New York: McGraw-Hill.

Mintzberg, Henry. 1973. The Nature of Managerial Work. New York: Harper \& Row.

Nalbandian, John. 1994. Reflections of a "Pracademic" on the Logic of Politics and Administration. Public Administration Review 54(6): 531-36

National Commission on the Public Service (Volcker Commission). 1990. Leadership for America. Lexington, MA: Lexington Books.

Neider, Linda L., and Chester A. Schriesheim. 1988. Making Leadership Effective: A Three-Stage Model. Journal of Management Development 7(5): 10-20.

Nunnally, Jum C. 1978. Psychometric Theory. 2nd ed. New York: McGraw-Hill.

Pallant, Julie. 2005. SPSS Survival Manual: A Step by Step Guide to Data Analysis Using SPSS for Windows. 2nd ed. New York: Open University Press.

Pearce, Craig L., and Jay A. Conger, eds. 2003. Shared Leadership: Reframing the Hows and Whys of Leadership. Thousand Oaks, CA: Sage Publications. Peters, Tom. 1994. The Pursuit of WOW! Every Person's Guide to Topsy-Turvy Times. New York: Vintage Books.

Peters, Tom, and Nancy Austin. 1985. A Passion for Excellence: The Leadership Difference. New York: Random House.

Podsakoff, Philip M., William D. Todor, and Richard Skov. 1982. Effects of Leader Contingent Reward and Noncontigent Reward and Punishment Behaviors on Subordinate Performance and Satisfaction. Academy of Management Journal 25(4): 810-21.

Porter, Lyman W., and Edward E. Lawler. 1968. Managerial Attitudes and Performance. Homewood, IL: R.D. Irwin.

Rainey, Hal G., and Steven A. Watson. 1996. Transformational Leadership and Middle Management: Towards a Role for Mere Mortals. International Journal of Public Administration 19(6): 763-800.

Rankin, Neil. 2001. Raising Performance through People: The Eighth Competency Survey. Competency and Emotional Intelligence 2: $2-23$.
Roberts, Nancy C., and Raymond Trevor Bradley. 1988. Limits of Charisma. In Charismatic Leadership: The Elusive Factor in Organizational Effectiveness, edited by Jay A. Conger and Rabindra N. Kanungo, 253-75. San Francisco: Jossey-Bass.

Roethlisberger, Fritz J., and William J. Dickson. 1939. Management and the Worker. Cambridge, MA: Harvard University Press.

Romzek, Barbara S. 1990. Employee Investment and Commitment: The Ties That Bind. Public Administration Review 50(3): 374-82.

Rost, Joseph C. 1990. Leadership for the Twenty-First Century. New York: Praeger.

Schein, Edgar H. 1985. Organizational Culture and Leadership. San Francisco: Jossey-Bass.

Selznick, Philip. 1957. Leadership in Administration: A Sociological Interpretation. Evanston, IL: Row, Peterson.

Senge, Peter M. 1990. The Fifth Discipline: The Art and Practice of the Learning Organization. New York: Doubleday/Currency.

Stogdill, Ralph M. 1974. Handbook of Leadership: A Survey of Theory and Research. New York: Free Press.

Stone, Donald C. 1945 . Notes on the Government Executive: His Role and His Methods, Public Administration Review 5(3): 210-25.

- 1981. Innovative Organizations Require Innovative Managers. Public Administration Review 41(5): 507-13

Terry, Larry D. 1995. Leadership of Public Bureaucracies: The Administrator as Conservator. Thousand Oaks, CA: Sage Publications.

Terry, Robert W. 1993. Authentic Leadership: Courage in Action. San Francisco: Jossey-Bass.

Tichy, Noel M., and Mary Anne Devanna. 1986. The Transformational Leader. New York: Wiley.

U.S. Office of Personnel Management (OPM). 1997. MOSAIC: Occupational Study of Federal Executives, Managers, and Supervisors. Washington, DC: Office of Personnel Management.

- 1999. High-Performing Leaders: A Competency Model. Washington, DC: Office of Personnel Management.

—. 2002. Federal Human Capital Survey 2002. http://www.fhcs.opm.gov [accessed November 23, 2004].

. 2003. What Federal Employees Say: Results from the 2002 Federal Human Capital Survey. http://www.fhcs.opm.gov/what.htm [accessed November 23, 2004]

Van Wart, Montgomery. 2003. Public Sector Leadership Theory: An Assessment. Public Administration Review 63(2): 214-28. 2005. Dynamics of Leadership in Public Service: Theory and Practice. Armonk, NY: M.E. Sharpe. 
Van Wart, Montgomery, and Evan M. Berman. 1999.

Contemporary Public Sector Productivity Values:

Narrower Scope, Tougher Standards, and New

Rules of the Game. Public Productivity and

Management Review 22(3): 326-47.

Yukl, Gary A. 1999. An Evaluative Essay on Current

Conceptions of Effective Leadership. European
Journal of Work and Organizational Psychology 8(1):

$33-48$.

2002. Leadership in Organizations. 5th ed. Upper Saddle River, NJ: Prentice Hall.

Zaleznik, Arthur. 1977. Managers and Leaders: Are

They Different? Harvard Business Review 55(5):

67-78.

\section{Get Your Own Copy of PAR!}

A subscription to PAR is a valuable benefit of membership in the American Society for Public Administration (ASPA), the international network of practitioners and scholars dedicated to excellence in public service.

Visit www.aspanet.org for information on joining ASPA! 